\title{
IN VITRO RELEASE MODELING OF ASPIRIN FLOATING TABLETS USING DDSOLVER
}

\begin{abstract}
Agus Siswanto ${ }^{1,2}$, Achmad Fudholi ${ }^{1 *}$, Akhmad Kharis Nugroho ${ }^{1}$, Sudibyo Martono ${ }^{1}$
1Faculty of Pharmacy, Universitas Gadjah Mada Sekip Utara Jogjakarta 55281, Indonesia

2Faculty of Pharmacy, Muhammadiyah University of Purwokerto, Jl. Raya Dukuh Waluh Purwokerto 53142, Indonesia

Submitted: $14-01-2015$

Revised: 10-02-2015

Accepted: $25-03-2015$

*Corresponding author Achmad Fudholi

Email:

fudholiugm@yahoo.com

ABSTRACT

Aspirin has low solubility in water therefore, dissolution is a rate limiting step for absorption. Floating tablet formulation is designed to improve the bioavailability of aspirin. The objective of this study was to determine in vitro dissolution study of aspirin floating tablet release kinetics model. The floating tablets were prepared by a direct compression method using Methocel K4M CR, $\mathrm{NaHCO}_{3}$, Ethocel, Aerosil, and dicalcium phosphate anhydrous as excipients. Tablets were evaluated by different parameters such as physicochemical properties, floating lag time $\left(F_{\text {lag time }}\right)$, total floating time, and dissolution. The result showed that the tablet mass has good flow properties of $13.54 \mathrm{~g} / \mathrm{sec}$. Aspirin floating tablets had a weight uniformity $(\mathrm{CV}=1.45 \%)$, good hardness $(6.42 \mathrm{~kg})$, and low friability $(0.158 \%)$. The tablet has a short $F_{\text {lag }}$ time of $25.16 \mathrm{sec}$ and long floating time of 8 hours. Dissolution data were evaluated using DDSolver conducted by (1) Statistical parameters: $\mathrm{R}^{2}$ adjusted, AIC, MSC; (2) Visual goodness of fit (GOF). The results showed that aspirin floating tablets release kinetics followed the Korsmeyer-Peppas model. Aspirin release occurs through the mechanism of anomalous transport which combines Fickian diffusion and polymer relaxation.
\end{abstract}

Key words: aspirin floating tablet, DDSolver, modeling of drug release

\section{INTRODUCTION}

Aspirin is used as an antiplatelet for stroke prophylaxis (Laurer, 2002; Awtry and Loscalzo, 2000; Patrono and Rocca, 2008). Aspirin prevents blood from clotting by inhibiting cyclooxygenase, the enzyme responsible for the formation of thromboxane A2, which is a mediator of platelet aggregating (Kannan et al., 2010; Awtry and Loscalzo, 2000).

Aspirin has a low bioavailability due to first-pass effect and hydrolysis to salicylate metabolism in the gut wall (Sweetman, 2009). Aspirin is rapidly absorbed in the upper gastrointestinal tract, especially in the portion of the small intestine (Awtry and Loscalzo, 2000; Sweetman, 2009). Therefore, formulation of floating drug delivery system (floating on the gastric fluid) are designed to improve the bioavailability of aspirin (Suratri, 2008).

Aspirin has low solubility in water (1:300) (Moffat et al., 2011; Sweetman, 2009) therefore, dissolution is one of the rate limiting step in their absorption and bioavailability (Gordon et al., 1994; Wells, 2002). Information on the mechanisms and kinetics of dissolution is important to estimate the absorption of aspirin floating tablet. Several mathematical models were developed to analyze dissolution data such as the zero-order, first-order, Higuchi, Weibull, Korsmeyer-Peppas, HixsonCrowell, Baker-Lonsdale, and Hopfenberg. The nonlinear fitting of dissolution data can be performed using a professional statistical programs such as Micro-Math Scientist, GraphPad Prism, SigmaPlot, or SYSTAT. However, these programs require the user to define the equations manually and need the initial value for each parameter (Zhang et al., 2010). DDSolver is a new software developed for the kinetic analysis of dissolution data (Murtaza et al., 2012) with a non-linear regression approach. DDSolver is a menudriven add-in program for Microsoft Excel written in Visual Basic for Applications. Calculation using Excel offers a number of advantages over other software. The most attractive of advantages is the easy of use. Most scientists are already familiar with Excel because of its wide availability 
and high flexibility (Zhang et al., 2010). This study was aimed to describe the dissolution data of aspirin floating tablet using DDSolver.

\section{MATERIAL AND METHODS}

Aspirin was obtained from Jilin Pharmaceutical Co. (Jilin, China), sodium bicarbonate from Tosoh Corporation (Tokyo, Japan), dicalcium phosphate anhydrous from Budenheim (Budenheim, Germany), Methocel K4M CR and Ethocel Premium Standard 20 from Colorcon Asia Pvt. Ltd. Hydrochloric acid and sodium chloride (analytical grade) were purchased from Merck (Darmstadt, Germany). All other chemicals used were of pharmaceutical grade.

\section{Preparation of floating tablet}

Tablets were prepared by direct compression method based on formulation in Table I. Aspirin, Methocel K4M CR, sodium bicarbonate, Ethocel, dicalcium phosphate anhydrous, and Aerosil were mixed in a cube mixer at $30 \mathrm{rpm}$ for $3 \mathrm{~min}$. The tablet compression process used single punch tablet machine (Korsch, Germany). The weight of tablets were arranged at $200 \mathrm{mg}$ and the hardness of tablet were controlled at $6-8 \mathrm{~kg}$ (Monsanto hardness tester).

Table I. Formulation of aspirin floating tablet

\begin{tabular}{lc}
\hline Ingredient & $\begin{array}{c}\text { Amount (mg) / } \\
\text { tablet }\end{array}$ \\
\hline Aspirin & 80.00 \\
Methocel K4M CR & 33.87 \\
$\mathrm{NaHCO}_{3}$ & 30.37 \\
Ethocel & 35.76 \\
Aerosil & 2.00 \\
Dicalcium & 18.00 \\
phosphate & \\
anhydrous & \\
\hline Total weight (mg) & 200.0 \\
\hline
\end{tabular}

\section{Physical properties of floating tablet}

Weight variation: Twenty tablets were randomly selected from the batch and weighed individually to check for weight variation. Hardness test: Monsanto hardness tester was used to determine the tablet hardness. Friability: About 20 tablets were selected from each batch and evaluated for friability using an abrasive tester (ERWEKA, Germany).

\section{Floating lag time ( $\left.\boldsymbol{F}_{\text {lag time }}\right)$}

Tablet was immersed in beaker containing $100 \mathrm{~mL}$ of simulated gastric fluid (SGF) without pepsin $\mathrm{pH}$ 1.2. Time required for the tablet to rise to the surface and floating was determined as floating lag time (Patel et al., 2007a).

\section{In vitro dissolution studies}

The in vitro dissolution study was determined using Erweka DT 600 USP apparatus II (paddle method), using $900 \mathrm{~mL}$ SGF without pepsin $\mathrm{pH} 1.2$ as dissolution medium at $37 \pm 0.2^{\circ} \mathrm{C}$ and $60 \mathrm{rpm}$ (USP XXXII, 2008; Gopalakrishnan and Chenthilnathan, 2011). Aliquouts of $5 \mathrm{~mL}$ was taken out at intervals of $15,30,45,60,120,180,240,300$, 360,420 , and $480 \mathrm{~min}$. Exactly $5 \mathrm{~mL}$ of fresh SGF was added to the dissolution vessel after each withdrawal to maintain a constant volume. The samples were analyzed by UVVis spectrophotometer (Genesys 10 Thermo) at $280 \mathrm{~nm}$.

\section{Determination of drug content}

Twenty tablets were taken randomly from the batch, weighed, and powdered. A $200 \mathrm{mg}$ of powder equivalent to $80 \mathrm{mg}$ of aspirin was put into a $100 \mathrm{~mL}$ flask. Two $\mathrm{mL}$ of absolute ethanol and simulated gastric fluid (without pepsin) were added up to the mark. The solution was centrifuged for $60 \mathrm{~min}$, then filtered with filter paper. The drug content was analyzed at the wavelength of aspirin (278nm) and salicylic acid (304nm) using a UV-Vis spectrophotometer. Drug content was then calculated with a simultaneous spectrophotometric method.

\section{Data analysis}

Physicochemical and floating properties were evaluated based on the applicable requirements. The dissolution data modeling was calculated using DDSolver. Evaluation of release kinetics model was conducted by (1) statistical parameters: $\mathrm{R}^{2}$ adjusted, Akaike Information Criterion (AIC), Model Selection Criterion (MSC); and (2) Visual goodness of fit (GOF). 


\section{RESULTS AND DISCUSSION The physicochemical properties of aspirin floating tablets}

Aspirin floating tablets have good physicochemical properties (Table II). The tablets have a uniform weight with $\mathrm{CV}=1.45 \%$ so the active substance in each tablet was uniform (Davies, 2009). Tablets have good hardness of $6.42 \mathrm{~kg}$ (Gordon et al., 1990) and low friability $(<1 \%)$ therefore, it withstand to mechanical shocks and not easily destroyed. The content of aspirin in floating tablets within the required USP XXXII (2008) range of 95$105 \%$.

Table II. Physicochemical properties of aspirin floating tablets

\begin{tabular}{lr}
\hline Parameters & Mean \pm SD \\
\hline Weight of tablet (mg) & $201.1 \pm 0.6$ \\
Friability $(\%)$ & 0.16 \\
Hardness (kg) & $6.42 \pm 0.58$ \\
$F_{\text {lag time }(\mathrm{sec})}$ & $25.16 \pm 4.60$ \\
Total floating time (hours) & $>8$ \\
Drug content (aspirin) $(\%)$ & $99.55 \pm 1.99$ \\
Drug content (salysilic & $1.24 \pm 0.09$ \\
acid) $(\%)$ & \\
\hline
\end{tabular}

\section{In vitro buoyancy of aspirin floating tablets}

One parameter of good floating tablet quality is the tablet's ability to float in the medium indicated by $\mathrm{F}_{\text {lag time }}$ and floating time. The duration of floating indicates the time of tablets float in the dissolution medium. Aspirin floating tablets was able to float during dissolution test, intact and not eroded. This indicates that the floating tablet of aspirin can release during dissolution testing. The composition of excipients used in the formulation was able to maintain the floating ability and the integrity of the tablets. Ethocel, aerosil, and dicalcium phosphate anhydrous are hydrophobic excipients that play a role in the maintaining of integrity of the tablets in the dissolution medium.

$F_{\text {lag time }}$ indicates the speed of tablet to float in the dissolution medium. $F_{\text {lag time test }}$ (Table II) showed that aspirin floating tablets within the requirements of less than 180 seconds (Patel et al., 2007a). The sooner the tablet floats, the better the floating quality.
Buoyancy was determined by the density of tablet. If the density is less than 1, the tablets will float properly (Patel et al., 2007a; Dave et al., 2004). Aspirin floating tablet buoyancy is determined by the composition of Methocel K4M CR, $\mathrm{NaHCO}_{3}$, and Ethocel as excipients. When $\mathrm{NaHCO}_{3}$ reacts with SGF, the $\mathrm{CO}_{2}$ gas was produced. Gas trapped in a hydrophilic gel Methocel K4M CR thereby, decreasing the density of the tablets (Patel et al., 2007b). Ethocel, which is hydrophobic, will maintain the integrity of tablet to float in a long time. Therefore, the combination of these three excipients produced a floating tablet with short $\mathrm{F}_{\text {lag-time }}$ and long floating duration.

\section{In vitro dissolution profiles of aspirin floating tablets}

Aspirin floating tablet dissolution test was conducted according to USP XXXII (2008). Aspirin tablets were designed to float in the stomach for a long time. Drug release will occur in the gastric; therefore, the SGF (without pepsin) pH 1.2 was used as dissolution test medium. The dissolution profile was made by plotting the percentage of drug dissolved versus time (Figure 1). The amount of aspirin dissolved in the 60 minutes is $22.73 \%$ within USP XXXII (2008) range of 20-55\%. The amount of aspirin released after $8 \mathrm{~h}$ was $84.85 \%$.

\section{Dissolution study of aspirin floating tablet release using DDSolver}

In vitro drug release data were fitted to kinetics models such as the zero-order, firstorder, Higuchi, Weibull, Korsmeyer-Peppas, Hixson-Crowell, Baker-Lonsdale, and Hopfenberg using DDSolver. The input of dissolution data into DDSolver include: (1) percentage of drug dissolved, (2) dissolution time (minutes). Modeling dissolution by DDSolver were estimated by nonlinear regression in accordance with the equation in table III.

Analysis model of visual goodness of fit (GOF) conducted in two methods: (1) the correlation of Qo (amount of aspirin dissolved in the experimental results) versus Qc (the predicted amount of aspirin dissolved in the medium) (Figure 2); (2) the correlation of residuals versus time (Figure 3) (Nugroho et al., 2014). 
Table III. Models available in DDSolver for fitting drug release data

\begin{tabular}{ll}
\hline Model & Equation \\
\hline Zero order & $\mathrm{F}=\mathrm{k}_{0} \mathrm{t}$ \\
First order & $\mathrm{F}=100\left[1-\operatorname{Exp}\left(-\mathrm{k}_{1} \mathrm{t}\right)\right]$ \\
Higuchi & $\mathrm{F}=\mathrm{k}_{\mathrm{H}} \mathrm{t}^{0.5}$ \\
Hixson-Crowell & $\mathrm{F}=100\left[1-\left(1-\mathrm{k}_{\mathrm{HC}} \mathrm{t}\right)^{3}\right]$ \\
Hopfenberg & $\mathrm{F}=100\left[1-\left(1-\mathrm{k}_{\mathrm{HB}} \mathrm{t}\right)^{\mathrm{n}}\right]$ \\
Weibull & $\mathrm{F}=100\left\{1-\mathrm{Exp}\left[-\left(\mathrm{t}^{\beta}\right) / \alpha\right]\right\}$ \\
Korsmeyer-Peppas & $\mathrm{F}=\mathrm{k}_{\mathrm{KP}} \mathrm{t}^{\mathrm{n}}$ \\
Baker-Lonsdale & $3 / 2\left[1-(1-\mathrm{F} / 100)^{(2 / 3)}\right]-\mathrm{F} / 100=\mathrm{k}_{\mathrm{BL}} \mathrm{t}$ \\
\hline
\end{tabular}

Note: $\mathrm{F}=$ drug released $(\%) ; \mathrm{t}=$ time (minutes)

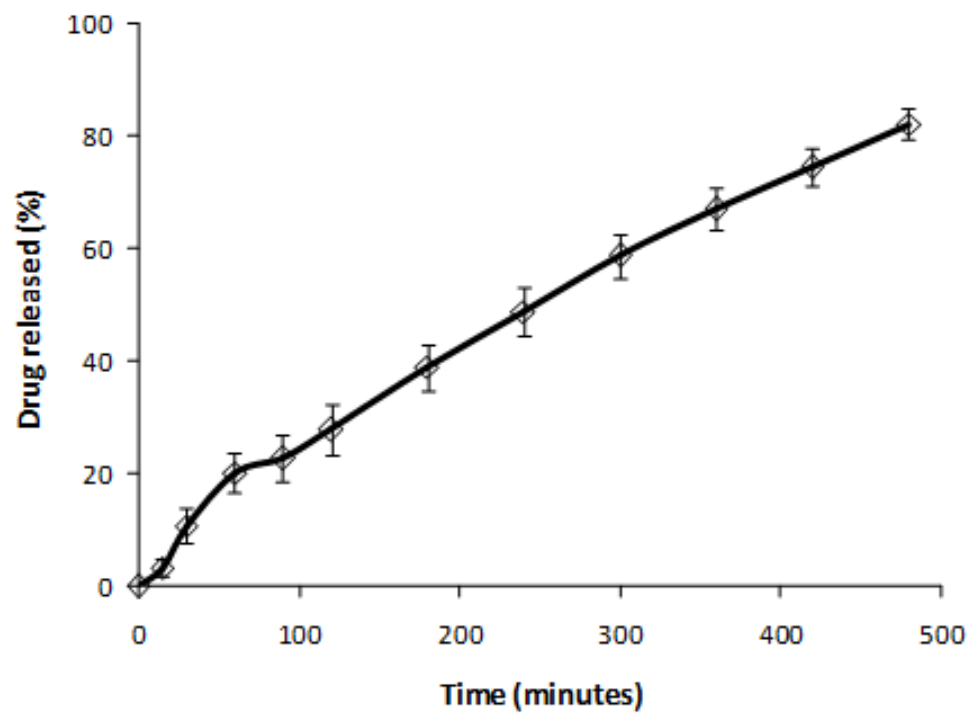

Figure 1. Drug release of aspirin floating tablets

Correlation analysis of Qo versus Qc in figure 2 showed that the Korsmeyer-Peppas model was the most appropriate model to explain the phenomenon of aspirin dissolution in floating tablet. Kormeyer-Peppas models provide the less deviation between Qo and Qc, so it appears in figure 2 that the distribution of dissolution data (Qo) beyond the curve of predicted dissolution data (Qc). Modeling kinetics of dissolution in zero-order, first-order, Higuchi, Weibull, Hixson-Crowell, BakerLonsdale, and Hopfenberg produced the more deviation of Qo and Qc. This is reinforced by the residual correlation analysis (Qo-Qc) versus time indicates that Korsmeyer-Peppas models do not form a specific pattern in figure 3 .
DDSolver provides a number of statistical criteria to evaluate the dissolution model included the correlation coefficient (R_obs-pre), the coefficient of determination (Rsqr, R2 , or COD), the adjusted coefficient of determination (Rsqr_adj or $\mathrm{R}^{2}$ adjusted), mean square error (MSE), standard deviation residuals (MSE_root or Sy.x), SS, WSS, Akaike Information Criterion (AIC), and Model Selection Criterion (MSC). Among these parameters, $\mathrm{R}^{2}$ adjusted, AIC, MSC are the most popular and widely used in the identification of dissolution data modeling (Zhang et al., 2010).

$$
\mathrm{R}^{2} \text { adjusted is the most appropriate }
$$
parameter for comparing dissolution models with different parameters compared to $\mathrm{R}^{2}$. 

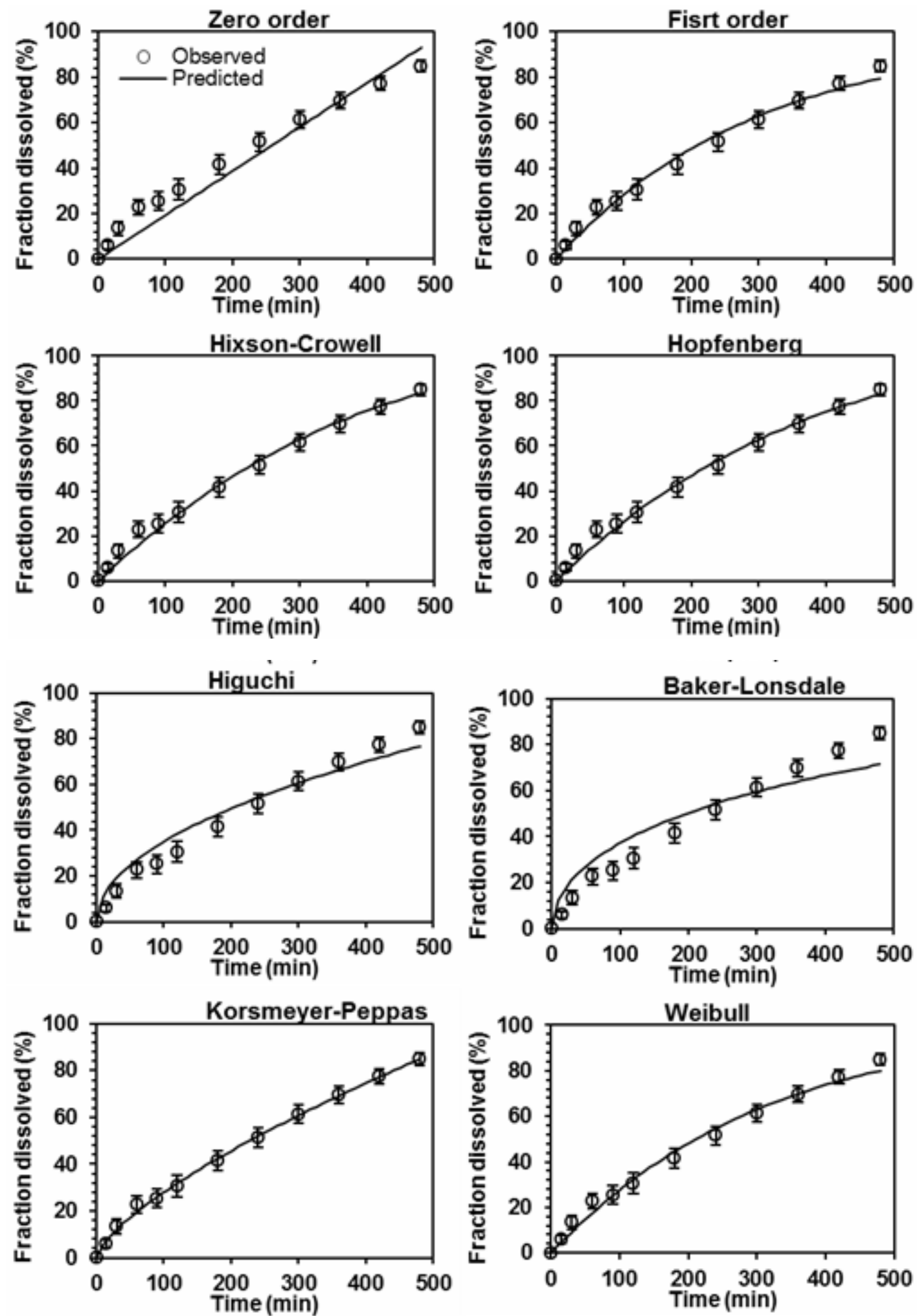

Figure 2. Observed data of drug release of aspirin floating tablets in dissolution studies, presented together with the model prediction using zero order, first order, Higuchi, Hixson-Crowell, Hopfenberg, Baker-Lonsdale, Korsmeyer-Peppas, and Weibull 

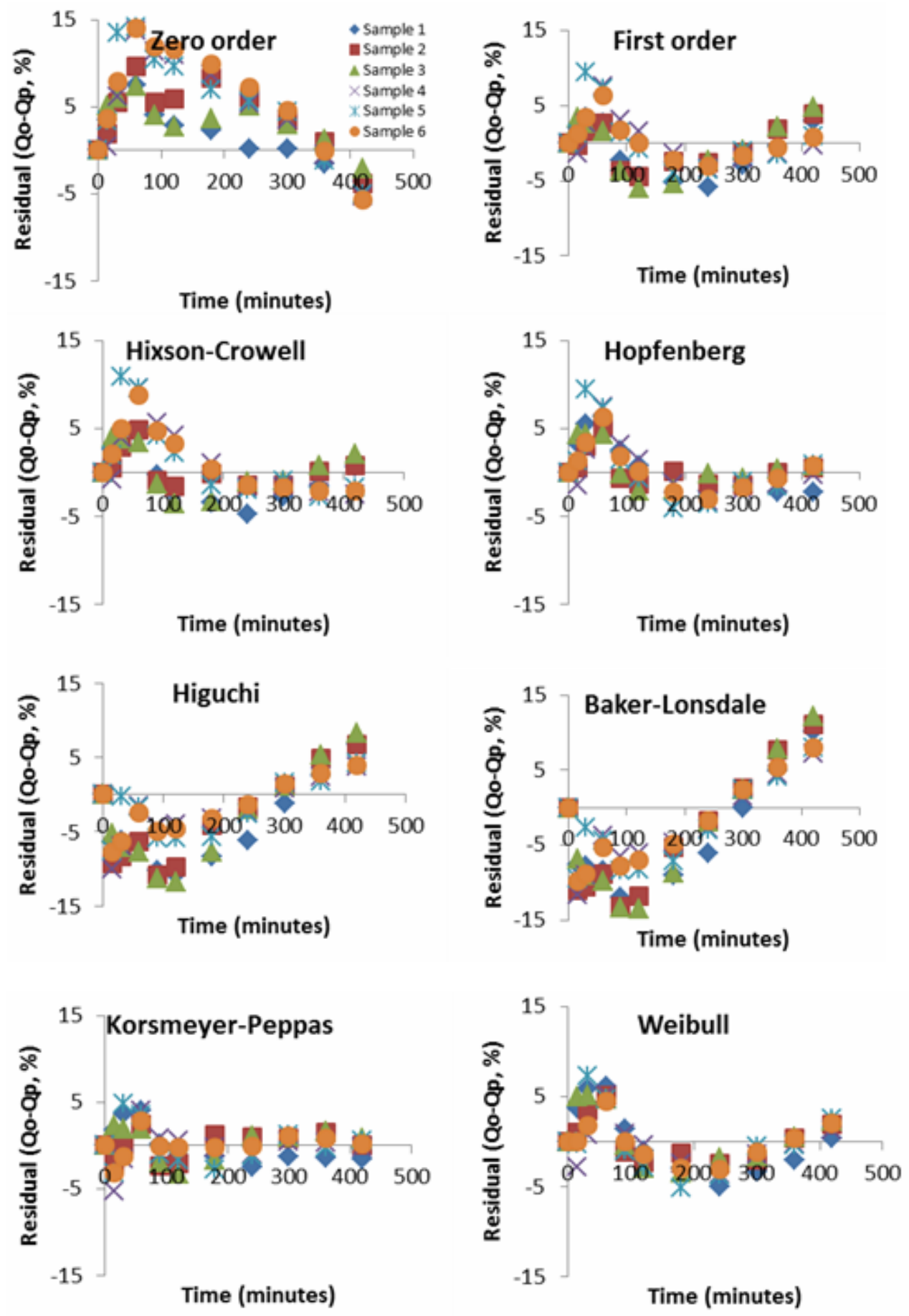

Figure 3. Goodness of fit (GOF) evaluations based on correlation of residual versus time indicating that Korsmeyer-Peppas models do not form a specific pattern 
In Vitro Release Modeling of Aspirin Floating Tablet

Table IV. Statistical parameters of models to describe release of aspirin floating tablets

\begin{tabular}{lccc}
\hline \multirow{2}{*}{ Model } & \multicolumn{3}{c}{ Statistical parameters of models (mean \pm SD) } \\
\cline { 2 - 4 } & $\mathbf{R}^{2}$ adjusted & AIC & MSC \\
\hline Zero order & $0.938 \pm 0.037$ & $75.38 \pm 8.65$ & $2.62 \pm 0.77$ \\
First order & $0.982 \pm 0.010$ & $61.35 \pm 5.98$ & $3.79 \pm 0.51$ \\
Higuchi & $0.951 \pm 0.027$ & $73.42 \pm 7.22$ & $2.79 \pm 0.55$ \\
Korsmeyer-Peppas & $0.994 \pm 0.002$ & $48.86 \pm 4.80$ & $4.83 \pm 0.46$ \\
Hixson-Crowell & $0.983 \pm 0.009$ & $60.26 \pm 7.91$ & $3.88 \pm 0.75$ \\
Hopfenberg & $0.988 \pm 0.007$ & $57.81 \pm 6.22$ & $4.09 \pm 0.60$ \\
Baker-Lonsdale & $0.910 \pm 0.033$ & $81.67 \pm 4.91$ & $2.10 \pm 0.35$ \\
Weibull & $0.985 \pm 0.009$ & $59.94 \pm 6.38$ & $3.91 \pm 0.55$ \\
\hline
\end{tabular}

Table V. Dissolution parameters of aspirin floating tablets by Korsmeyer-Peppas

\begin{tabular}{cc}
\hline Parameter & Mean \pm SD \\
\hline $\mathrm{k}_{\mathrm{KP}}$ & $1.175 \pm 0.562$ \\
$\mathrm{n}$ & $0.712 \pm 0.091$ \\
\hline
\end{tabular}

$\mathrm{R}^{2}$ adjusted value will decrease with the increasing of dissolution model parameters. The best model is the model with the highest value of $\mathrm{R}^{2}$ adjusted (Zhang et al., 2010). Based on $\mathrm{R}^{2}$ adjusted in table IV, Korsmeyer-Peppas is the most appropriate model for this study.

AIC parameters have been used for more than 35 years in the dissolution data analysis because it is simple and easy to use (Zhang et al., 2010). The model with the smallest AIC value is the most precise model (Motulsky and Christopoulos, 2003). The MSC is a modified reciprocal form of the AIC and has been normalized so that it is independent of the scaling of the data points. If we compared several models, the model with the highest value of the MSC is the best model. In general, the model was appropriate when the MSC value $>2$ or 3 (Zhang et al., 2010). Dissolution model parameters in table IV showed that the Korsmeyer-Peppas models is the best model to explain the phenomenon of aspirin floating tablet dissolution.

\section{Dissolution mechanism of aspirin floating tablet by Korsmeyer-Peppas}

Korsmeyer-Peppas dissolution models

explain the exponential relationship of dissolved drug fraction versus time.

$\mathrm{F}=\mathrm{k}_{\mathrm{KP}} \mathrm{t}^{\mathrm{n}}$
$\mathrm{F}=$ fraction of drug dissolved at time $\mathrm{t}, \mathrm{a}=$ drug dissolution constant, $\mathrm{t}=$ dissolution time (minutes), and $\mathrm{n}=$ dissolution exponent (Costa and Lobo, 2001).

Dissolution exponent (n) can be used to explain the mechanisms involved in the dissolution (Kalam et al., 2007). The analysis result of aspirin floating tablet dissolution with Korsmeyer-Peppas gave $\mathrm{n}$ value of 0.712 (Table V). For cylindrical dosage form (tablets) then $0.45<\mathrm{n}<1$ indicates that dissolution occurs through the mechanism of anamalous transport (Costa and Lobo, 2001; Colombo et al., 2000). The release of aspirin from floating tablet occurs through the combination of Fickian diffusion and polymer relaxation. The dissolution of aspirin was influenced by the excipients in the tablet. Methocel K4M CR is a hydrophilic polymer HPMC. When it contacted with SGF, Methocel K4M CR will expand to form a thick gel. $\mathrm{NaHCO}_{3}$ reacts with dissolution medium (SGF) produces $\mathrm{CO}_{2}$ which form pores in the polymer gel Methocel K4M CR. Ethocel, which is hydrophobic, will maintain the integrity of the tablets to withdraw the massive erosion. Therefore, the release of aspirin occurs through Fickian diffusion pass through hydrophilic gel. The dissolution of aspirin was also determined by the relaxation ability of Methocel K4M CR and Ethocel in the medium. 


\section{CONCLUSION}

Based on the results it can be concluded that aspirin floating tablets fulfilled the requirements of good quality tablet. The dissolution data evaluated with DDSolver showed that the kinetics release of floating tablets followed the Korsmeyer-Peppas model through anomalous transport mechanism which combines Fickian diffusion and polymer relaxation.

\section{ACKNOWLEDGMNET}

The authors express their sincere thanks to Faculty of Pharmacy, Universitas Gadjah Mada, and Faculty of Pharmacy, Muhammadiyah University of Purwokerto for supporting this research.

\section{REFERENCES}

Awtry EH., Loscalzo J., 2000, Aspirin, Circulation, 101, 1206-1218

Costa P., Lobo JMS., 2001, Review Modeling and comparison of dissolution profiles, Eur. J.Pharm. Scie., 13,123-133

Colombo P., Santi P., Bettini R., Brazel CS., Peppas NA., 2000, Drug Release from Swelling-Controlled System, in Wise, D.L., Handbook of Pharmaceutical Controlled Technology, Marcel Dekker Inc., New York. pp 183-205

Dave BS., Amin AF., Patel MM., 2004, Gastroretentive Drug Delivery System of Ranitidine Hydrochloride:Formulation and In Vitro Evaluation, AAPS PharmSciTech, 5(2), 1-6

Davies P., 2009, Oral Solid Dosage Form, In Gibson M., Pharmaceutical Preformulation and Formulation, Informa healtcare, New York. pp 389

Fudholi A., 1983, Methodology Formulation in Direct Compression, Medika, 7(9), 586593

Gopalakrishnan, S., Chenthilnathan, A., 2011, Floating Drug Delivery Systems: A Review, J. Pharm. Scie. Tec., 3(2), 548-554.

Gordon RE., Rosanke TW., Fonner DE., Anderson NR., Banker GS., 1990, Granulation Technology and Tablet Characterization, in Lieberman, H.A., Lachman, L., Schwartz, J.B., Pharmaceutical Dosage Form: Tablet, $2^{\text {nd }}$ Ed., Vol 2, Marcel Dekker Inc., New York. pp 327-332

Gordon MS., Ellis DJ., Molony B., 1994, In Vitro Dissolution Versus In Vivo Evaluation of Four Different Aspirin Products, Drug Dev. Ind. Pharm., 20(10), 1711-1723

Kannan S., Manivannan R., Balasubramaniam A., Kumar NS., 2010, Formulation and Evaluation of Aspirin Delayed Release Tablet, IJCP, 01, accessed 12.02.12, $<$ http://www.pharmacie-globale.info $>$

Kalam MA., Humayun M., Parvez N., Yadaz S., Garg A., Amin S., Sultana Y., Ali A., 2007, Release Kinetics of Modified Pharmaceutical Dosage Forms: A Review, J.Pharm.Sciences, 1, 30-35

Lauer MS., 2002, Aspirin For Primary Prevention of Coronary Events, $N$ EnglJ Med, 346(19), 1468-1474

Moffat AC., Osselton MD., Widdop B., Watts J., 2011, Clarke's Analysis of Drugs and Poisons in Pharmaceuticals, Body Fluids and Postmortem Material, fourth edition, Pharmaceutical Press, London-Chicago. pp 924-926

Motulsky HJ., Christopoulos A., 2003, Fitting Models To Biological Data Using Linear and Nonlinear Regression. A Practical Guide To Curve Fitting, GraphPad Software, Inc., San Diego CA. pp 143-148

Murtaza G., Ahmad M., Khan SA., Hussain I., 2012, Evaluation of Cefixime-Loaded Chitosan Microspheres: Analysis of Dissolution Data Using DDSolver, Dissolution Technologies, 13-19

Nugroho AK., Binnarjo A., Hakim AR., Ermawati Y., 2014, Compartmental Modeling Approach of Losartan Transdermal Transport In Vitro, Indonesian J. Pharm., Vol. 25 No. 1, 31-38

Patel DM., Patel NM., Pandya NN., Jogani, PD., 2007a, Gastroretentive Drug Delivery System of Carbamazepine: Formulation Optimization Using Simplex Lattice Design: A Technical Note, AAPS PharmSciTech, 8(1), E1:E5, accessed 24.10.11, $<$ http://www.aapspharmscitech.org $>$

Patel VF., Patel NM., 2007b, Statistical Evaluation of Influence of Viscosity and 
Content of Polymer on Dipyridamole Release From Floating Matrix Tablets: A Technical Note, AAPS PharmSciTech, 8(3), E2-E5, accessed 24.10.11, <http://www.aapspharmscitech.org>

Patrono C., Rocca B., 2008, Aspirin: Promise and Resistance in the New Millennium, Arterioscler Thromb Vasc Biol, 28, s25-s32, accessed $<$ http://atvb.ahajournals.org $>$.

Suratri A., 2008, Floating Drug Delivery Systems To Increase Gastric Retention of Drugs: A Review, RJPT, 1(4), accessed 02.04.11, $<$ http://www.rjptonline.org/>.

Sweetman SC., 2009, Martindale The Complete Drug Reference, Thirty-sixth edition, Pharmacentical Press, London. pp 20-25
USP, 2008, United States Pharmacopeial XXXII, accessed 17.02.12, <http://www.pharmacopeia.cn/>.

Wells J., 2002, Pharmaceutical preformulation: The Physicochemical Properties of Drug Substances, in Aulton, M.E., Pharmaceutics: The Science of Dosage Form Design, Ed. II, Churcibill Livingstone, Edinburg. pp 113-138

Zhang Y., Huo M., Zhou J., Zou A., Li W., Yao C., Xie S., 2010, DDSolver: An Add-In Program for Modeling and Comparison of Drug Dissolution Profiles, The AAPS Journal, Vol. 12 No. 3, 263-271 